\title{
Chrysophanol administration alleviates bleomycin-induced pulmonary fibrosis by inhibiting lung fibroblast proliferation and $\mathbf{W n t} / \boldsymbol{\beta}$-catenin signaling
}

\author{
Xiangwei Qi ${ }^{1}$, Yamei Ou², Ying Xie ${ }^{2}$, Kangrong Cai ${ }^{3}$, Hualin Gan ${ }^{4}$, Qiqi Wan ${ }^{4}$, \\ Hao Xie ${ }^{4}$, Zeqing Song ${ }^{2 *}$ \\ ${ }^{1}$ Second Clinical Medical Skills Training Center, GuangDong Medical University, Dongguan City, Guangdong Province 523808, \\ ${ }^{2}$ Department of Respiratory Medicine, Shenzhen Longhua District Central Hospital, Shenzhen City, Guangdong Province \\ 518000, ${ }^{3}$ Analytical Center, GuangDong Medical University, Dongguan City, Guangdong Province 523808, ${ }^{4}$ Department of \\ Respiratory Medicine, The Fourth People's Hospital of Nanhai, Foshan City, Guangdong Province 528211, China
}

*For correspondence: Email: ZeqingSongghj@163.com; Tel: +86-755-21014681

Sent for review: 8 January 2020

Revised accepted: 27 April 2020

\begin{abstract}
Purpose: To determine the functional effect of chrysophanol (CH) on bleomycin (BLM)-induced pulmonary fibrosis (PF) and reveal its mechanism of action.

Methods: A mouse model of PF was established by intratracheal instillation of BLM (5 mg/ $\mathrm{kg})$, prior to $\mathrm{CH}$ administration. Masson's trichrome staining was used to analyze interstitial fibrosis and collagen deposition. Hydroxyproline (HYP) content was measured, and lung fibroblast viability determined by MTT assay. Bronchoalveolar lavage fluid (BALF) was collected, and levels of tumor necrosis factor- $\alpha$ (TNF- $\alpha$ ), interleukin-1 $\beta$ (IL-1 $\beta$ ), IL-6, and interferon- $\gamma$ (IFN- $\gamma$ ) were evaluated using enzyme-linked immunosorbent assays (ELISA). Expression of cell signaling, adhesion, and apoptotic proteins were determined by western blotting.

Results: Administration of $\mathrm{CH}$ reduced collagen deposition and HYP content, downregulated $\alpha$-smooth muscle actin, upregulated E-cadherin, and decreased the levels of TNF- $\alpha, I L-1 \beta, I L-6$, and IFN- $\gamma$ in $B L M$-treated mice. The viability of lung fibroblasts was also reduced, and Bcl-2-associated $X$ protein and cleaved caspase-3 were upregulated after $\mathrm{CH}$ treatment in BLM-treated mice. In addition, $\mathrm{CH}$ treatment in BLM-treated mice significantly increased levels of cytoplasmic $\beta$-catenin but decreased its expression in the nucleus.

Conclusion: Administration of $\mathrm{CH}$ alleviated BLM-induced PF by inhibiting lung fibroblast proliferation and nuclear translocation of $\beta$-catenin. Thus, this study provides a potential therapeutic strategy for PF.
\end{abstract}

Keywords: Chrysophanol, Bleomycin, Pulmonary fibrosis, Hydroxyproline, E-cadherin

\begin{abstract}
This is an Open Access article that uses a fund-ing model which does not charge readers or their institutions for access and distributed under the terms of the Creative Commons Attribution License (http://creativecommons.org/licenses/by/4.0) and the Budapest Open Access Initiative (http://www.budapestopenaccessinitiative.org/read), which permit unrestricted use, distribution, and reproduction in any medium, provided the original work is properly credited.
\end{abstract}

Tropical Journal of Pharmaceutical Research is indexed by Science Citation Index (SciSearch), Scopus, International Pharmaceutical Abstract, Chemical Abstracts, Embase, Index Copernicus, EBSCO, African Index Medicus, JournalSeek, Journal Citation Reports/Science Edition, Directory of Open Access Journals (DOAJ), African Journal Online, Bioline International, Open-J-Gate and Pharmacy Abstracts

\section{INTRODUCTION}

Pulmonary fibrosis (PF) is a progressive disorder characterized by pathological destruction of lung tissue architecture and extracellular matrix (ECM) accumulation in the interstitial and alveolar spaces [1]. Idiopathic PF (IPF), a diffuse lung condition with chronic progressive fibrosis, 
is a fibroproliferative disease that manifests as chronic damage of alveolar epithelial cells and abnormal tissue repair, leading to fibroblastic foci formation [2]. However, the etiology and pathogenesis of IPF remain unclear, and effective treatments to prolong the survival of patients with IPF are lacking. Therefore, exploring effective and novel therapies for IPF patients is of great importance. Rhubarb (Rheum palmatum $L$.), a traditional medicine in China, is widely used for treating various diseases [3,4]. Chrysophanol $(\mathrm{CH})$, an active ingredient of rhubarb, has potent anti-oxidative [5], antiinflammatory [6], and anti-diabetic [7] properties. In addition, a recent study found that $\mathrm{CH}$ exerted a protective effect against paraquat-induced lung injury via activation of peroxisome proliferatoractivated receptors (PPARs) [8]. Another study reported that $\mathrm{CH}$ could alleviate ovalbumininduced chronic lung toxicity by inhibiting Th17 cell responses [9]. However, the role of $\mathrm{CH}$ in bleomycin (BLM)-induced PF is poorly understood. The Wnt signaling pathway plays a pivotal role in various biological processes, tissue and organ homeostasis, organogenesis, embryogenesis, and the development of human cancers [10]. $\beta$-catenin mediates the Wnt pathway, and accumulation of nuclear $\beta$-catenin contributes to systemic sclerosis-associated fibrosis [11]. A recent study reported that aberrant Wnt/ $\beta$-catenin signaling could promote organ fibrosis development [12]. Excessive expression of $\beta$-catenin was also observed in hepatic fibrosis, and inactivation of $\mathrm{Wnt} / \beta$-catenin signaling prevented the activation of hepatic stellate cells [13]. These findings raised the possibility that the role of $\mathrm{CH}$ in BLM-induced PF may be associated with Wnt/ $\beta$-catenin signaling. To verify this relationship, a mouse model of pulmonary fibrosis was established via BLM treatment, and the underlying mechanism of $\mathrm{CH}$ activity was investigated.

\section{EXPERIMENTAL}

\section{Induction of PF model}

Male C57BL/6 mice $(n=18 ; 8$ weeks of age; weight: $20 \pm 2 \mathrm{~g}$ ) were obtained from Charles River Laboratory Animal Co., Ltd. (Wilmington, MA, USA) and housed in standard laboratory cages for 3 days prior to experiments. The experimental protocol conformed to the National Institutes of Health (NIH) Guide for the Care and Use of Laboratory Animals [14] and was approved by the institutional ethics committee of Guangdong Medical University(approval no. 2018065).
Mice were randomly assigned into three groups ( $n=6$ per group): sham operation (sham), BLM, and $\mathrm{BLM}+\mathrm{CH}$. BLM (5 mg/kg; Thermo Fisher Scientific, Inc., Waltham, MA, USA) was dissolved in saline and intratracheally instilled in the mice. After BLM challenge, mice were fed with $10 \mathrm{mg} / \mathrm{kg} /$ day $\mathrm{CH}$ (Seebio Biotech Company Ltd, Shanghai, China) for 4 weeks. Sham mice received the same volume of saline instead of $\mathrm{CH}$. At day 28, animals were sacrificed under general anesthesia by exsanguination. Pulmonary tissues were collected and frozen immediately in liquid nitrogen.

\section{Histopathological examination}

Pulmonary samples were fixed, embedded in paraffin, and sectioned into $5-\mu \mathrm{m}$ slices, followed by Masson's trichrome staining (Sangon Biotech, Inc., Shanghai, China). The slides were observed under a light microscope and analyzed using Image J software (NIH, Bethesda, MD, USA).

\section{Hydroxyproline (HYP) assay}

Assays were performed to quantify levels of HYP [15]. Briefly, pulmonary tissues were digested, diluted using papain solution to obtain a volume of $100 \mathrm{~mL}$, and incubated with $625 \mu \mathrm{L}$ chloramine-T, followed by addition of Ehrlich's solution $(625 \mu \mathrm{L})$ and incubation at $65^{\circ} \mathrm{C}$ for $20 \mathrm{~min}$. The reaction was quenched by immersion in cool water. Absorbance was measured at $550-565 \mathrm{~nm}$ with a spectrophotometer.

\section{Cell culture}

Mouse lung fibroblasts were obtained as reported previously [16]. The cells were maintained in F12K medium (MSKCC Media Facility, New York, NY, USA) containing 10\% fetal calf serum (Gibco, Grand Island, NY, USA), $1 \times$ low-serum growth supplement, $1 \%$ penicillin and streptomycin (Thermo Fisher Scientific) at at $37^{\circ} \mathrm{C}$ and $5 \% \mathrm{CO}_{2}$.

\section{Cell viability}

Cells $\left(1 \times 10^{4}\right.$ cells/well) were cultured in 48-well plates overnight. When cells reached $80 \%$ confluence, MTT assays were performed. Cell viability was assessed at $570 \mathrm{~nm}$ using a microplate reader (BioTek, Winooski, VT, USA).

\section{Cytokine measurement}

Bronchoalveolar lavage fluid (BALF) from each mouse was obtained by endotracheal intubation. After centrifugation, the cell-free supernatants 
were collected for measurement. Levels of tumor necrosis factor (TNF)- $\alpha$, interleukin (IL)-1 $\beta$, IL-6, and interferon (IFN)- $\gamma$ were determined using enzyme-linked immunosorbent assay (ELISA) kits (Abcam, MA, USA).

\section{Western blot analysis}

Pulmonary samples were homogenized, and proteins were extracted and quantified using a BCA Protein Assay kit (Thermo Fisher Scientific). Next, $10 \%$ SDS-PAGE was used to separate equal amounts of proteins, which were then transferred onto polyvinylidene difluoride membranes. The membranes were incubated with primary antibodies against $\alpha$-small muscle actin ( $\alpha$-SMA), E-cadherin, $\beta$-catenin, Bcl-2associated $X$ protein (Bax), and cleaved caspase-3 (BD Biosciences Franklin Lakes, NJ) overnight at $4^{\circ} \mathrm{C}$. The horseradish peroxidaseconjugated secondary antibody was added. Finally, an ECL detection system (GE Healthcare, Chicago, IL, USA) was utilized. The loading controls for cytoplasmic and nuclear proteins were $\alpha$-tubulin and Topoll $\beta$, respectively.

\section{Statistical analysis}

SPSS (Version 16.0) (SPSS Inc, Chicago, IL, USA) was utilized for all statistical analyses. The experimental data were reported as the mean \pm standard deviation (SD). One-way analysis of variance was utilized for comparison between multiple groups, followed by Tukey's multiple comparison tests. The cutoff for statistical significance was $p<0.05$.

\section{RESULTS}

\section{$\mathrm{CH}$ reduces ECM deposition in BLM-treated mice}

An overview of this experiment is shown in Figure $1 \mathrm{~A}$. Interstitial fibrosis and collagen deposition were visible in BLM-treated mice compared with sham mice $(p<0.01)$, while $\mathrm{CH}$ significantly reduced these effects (Figure $1 \mathrm{~B} ; p$ $<$ 0.05). BLM-induced HYP content also decreased after $\mathrm{CH}$ treatment $(p<0.05)$ (Figure $1 \mathrm{C}$ ). Western blotting analysis revealed that $\alpha-$ SMA levels were decreased, whereas E-cadherin expression was significantly increased in the $\mathrm{CH}+\mathrm{BLM}$ group compared to the BLM group ( $p<$ 0.01 ) (Figure $1 \mathrm{D})$. These results indicated that $\mathrm{CH}$ reduced $\mathrm{ECM}$ deposition in mice with $\mathrm{PF}$.

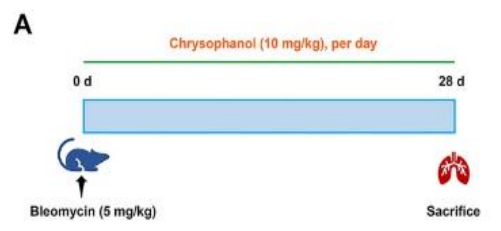

\section{B}

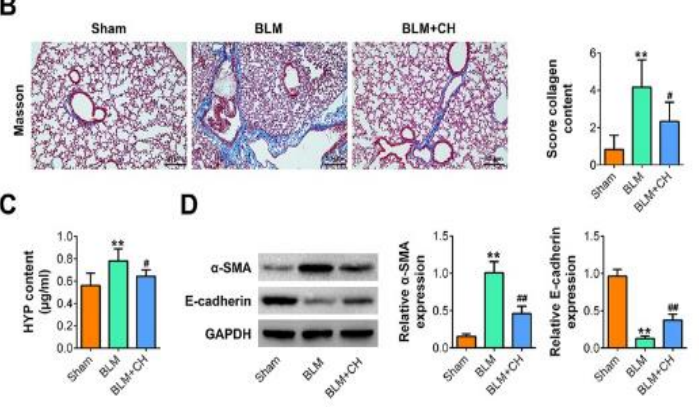

Figure 1: Effect of $\mathrm{CH}$ on ECM deposition in BLMtreated mice. (A) Experimental design overview. (B) Masson's trichrome staining of pulmonary samples. Scale bar $=50 \mu \mathrm{m}$. (C) HYP content measurement. (D) Western blotting and quantitation of protein expression; HYP, hydroxyproline; Sham, the sham operation group; BLM, the bleomycin group; BLM + $\mathrm{CH}$, the bleomycin plus chrysophanol group; ${ }^{* *} p<$ 0.01 , vs. sham; ${ }^{\#} p<0.05,{ }^{\#} p<0.01$ vs. BLM group

\section{$\mathrm{CH}$ attenuates BLM-induced pro-inflammatory cytokine expression in BALF from mice}

Compared with the sham group, BLM mice showed significantly increased levels of TNF- $\alpha$, IL-1 $1 \beta$, IL-6, and IFN- $\gamma$ levels in BALF $(p<0.01)$. The administration of $\mathrm{CH}$ significantly reduced expression of these inflammatory cytokines (Figure 2; $p<0.01$ or $p<0.05$ ).
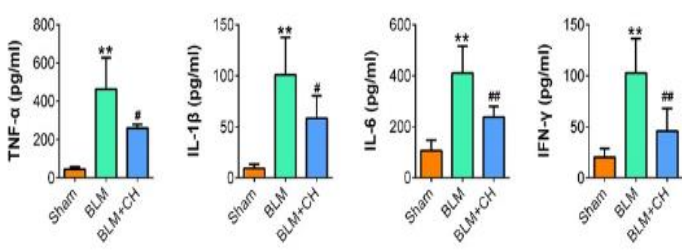

Figure 2: Effect of $\mathrm{CH}$ on inflammatory responses in BALF from BLM-treated mice. TNF- $\alpha$, tumor necrosis factor- $\alpha$; IL-1 $\beta$, interleukin 1; IL-6, interleukin 6; IFN- $\gamma$, interferon- $\gamma$. Sham, the sham operation group; BLM, the bleomycin group; BLM $+\mathrm{CH}$, the bleomycin plus chrysophanol group; ${ }^{* *} p<0.01$ vs. sham; ${ }^{\#} p<0.05$, ${ }^{\# \#} p$ $<0.01$ vs. BLM group

\section{$\mathrm{CH}$ inhibits BLM-induced nuclear transloca- tion of $\beta$-catenin in mice}

To investigate the mechanism of $\mathrm{CH}$ action, levels $\beta$-catenin of in the cytoplasm and nuclei of mouse lung fibroblasts was determined. BLM inhibited cytoplasmic expression of $\beta$-catenin but 
enhanced its nuclear expression. Treatment with $\mathrm{CH}$ increased levels of cytoplasmic $\beta$-catenin but decreased its levels in the nucleus (Figure 3 ).

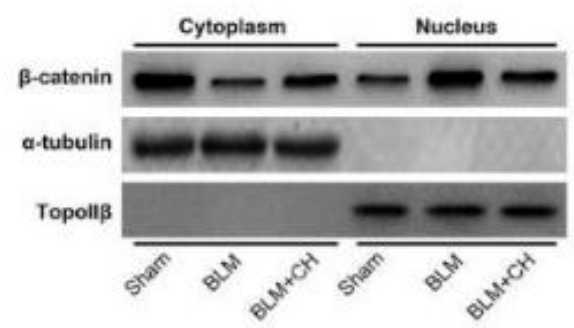

Figure 3: $\mathrm{CH}$ inhibits BLM-induced nuclear translocation of $\beta$-catenin in mice. Western blotting was used to determine the levels of $\beta$-catenin in the cytoplasm and nuclei of mouse lung fibroblasts. Sham, the sham operation group; BLM, the bleomycin group; $\mathrm{BLM}+\mathrm{CH}$, the bleomycin plus chrysophanol group

\section{$\mathrm{CH}$ inhibits viability of and induces apoptosis in BLM-treated lung fibroblasts}

Stimulation with BLM significantly increased the viability of and reduced protein levels of Bax and cleaved caspase-3 in lung fibroblasts $(p<0.01)$. After $\mathrm{CH}$ treatment, we observed a significant reduction in cell viability (Figure 4A). Western blotting analysis showed that $\mathrm{CH}$ treatment remarkably elevated the protein levels of Bax and cleaved caspase-3 (Figure 4 B-D).

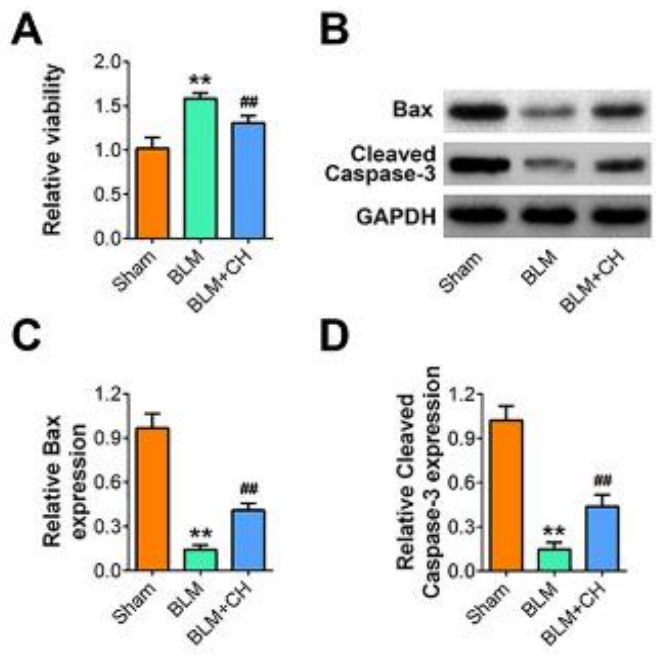

Figure 4: Effects of $\mathrm{CH}$ on the proliferation and apoptosis of lung fibroblasts. (A) MTT assays were used to measure the viability of lung fibroblasts. (B-D) Western blotting was used to measure levels of Bax and cleaved caspase-3.Sham, the sham operation group; BLM, the bleomycin group; $\mathrm{BLM}+\mathrm{CH}$, the bleomycin plus chrysophanol group; Bax, Bcl-2associated X protein; ${ }^{* *} p<0.01$ vs. sham; ${ }^{*} p<0.05$, $\#^{\#} p<0.01$ vs. BLM group

\section{DISCUSSION}

Idiopathic PF is a life-threatening lung disease with increasing incidence and prevalence [17]. Patients with IPF usually suffer from chronic and progressive exertional dyspnea and cough upon clinical presentation. Unfortunately, limited treatment options are available for IPF, highlighting the urgency to develop an optimal strategy for treating IPF. Increasing evidence shows that $\mathrm{CH}$ can alleviate lung injury by regulating PPAR or inflammatory responses $[8,9]$. However, few studies have discussed the possibility of treating IPF with $\mathrm{CH}$ administration. Thus, the current study was conducted to investigate the protective role and underlying mechanisms of $\mathrm{CH}$ action during IPF.

$\mathrm{CH}$ reportedly alleviates ovalbumin-induced expression of inflammatory cytokines, including TNF- $\alpha$, IL-4, IL-5, and IL-13, in the airways [18]. In addition, $\mathrm{CH}$ could ameliorate high-fat dietinduced injury and fibrosis in the heart by reducing collagen deposition and inflammatory responses [19]. Here, $\mathrm{CH}$ reduced ECM deposition and levels of inflammatory cytokines in a mouse model of PF.

Glioma cell apoptosis can be induced by tubeimoside-1 through regulation of Bax and Bcl2 expression and the reactive oxygen species/cytochrome c/caspase-3 pathway [20]. Matrine exerted anti-proliferative activity against cardiac fibroblasts by upregulating Bax and cleaved caspase-3 [21]. Doxorubicin decreased the viability of breast cancer cells and upregulated Bax, while downregulating Bcl-xL [22]. In a human lung adenocarcinoma cell line, 13-chlorine-3,15-dioxy-gibberellic acid methyl ester inhibited cell proliferation and induced cell apoptosis, accompanied by regulation of the mitochondrial apoptosis pathway through Bax upregulation [23]. In the present study, $\mathrm{CH}$ exerted an inhibitory effect on lung fibroblast proliferation. Treatment with BLM downregulated Bax and caspase-3, while $\mathrm{CH}$ increased Bax and caspase-3 expression levels, implying that $\mathrm{CH}$ attenuates PF by inhibiting cell proliferation.

Abnormal regulation of Wnt signaling is linked with the pathogeneses of various human fibrotic diseases in different organs. Hyperactive Wnt/ßcatenin signaling contributes to systemic sclerosis with observed elevated levels of nuclear $\beta$-catenin [24]. Aberrant activation of Wnt/ß-catenin signaling lead to IPF and accumulation of nuclear $\beta$-catenin in fibroblast foci [25]. William and colleagues [26] reported that nuclear $\beta$-catenin accumulation indicates activated Wnt signaling in IPF, which is 
attenuated by inhibiting the $W n t / \beta$-catenin/cyclic AMP response element binding protein pathway.

The results in this study were consistent with those of previous studies. In the current investigation, accumulation of nuclear $\beta$-catenin was observed after BLM challenge but decreased after $\mathrm{CH}$ treatment. These findings indicated that $\mathrm{CH}$ reversed BLM-induced IPF by inhibiting $W n t / \beta$-catenin signaling. Although these findings revealed that $\mathrm{CH}$ alleviates BLMinduced IPF in vitro, additional in vivo studies are needed. In addition, how $\mathrm{CH}$ inhibits PF via the $\mathrm{Wnt} / \beta$-catenin pathway warrants further investigation.

\section{CONCLUSION}

CF administration alleviates BLM-induced PF in mice via inhibition of $W n t / \beta$-catenin signaling pathway and suppression of lung fibroblast proliferation, thus providing a potential therapeutic strategy for IPF.

\section{DECLARATIONS}

\section{Conflict of interest}

No conflict of interest is associated with this work.

\section{Contribution of authors}

We declare that this work was done by the authors named in this article and all liabilities pertaining to claims relating to the content of this article will be borne by the authors.

\section{Open Access}

This is an Open Access article that uses a funding model which does not charge readers or their institutions for access and distributed under the terms of the Creative Commons Attribution License (http://creativecommons.org/licenses/by/ 4.0) and the Budapest Open Access Initiative (http://www.budapestopenaccessinitiative.org/rea d), which permit unrestricted use, distribution, and reproduction in any medium, provided the original work is properly credited.

\section{REFERENCES}

1. Wuyts WA, Agostini C, Antoniou KM, Bouros $D$, Chambers RC, Cottin V, Egan JJ, Lambrecht BN, Lories $R$, Parfrey $H$. The pathogenesis of pulmonary fibrosis: a moving target. Eur Respir J 2013; 41(5): 1207-1218.
2. Vancheri C. Common pathways in idiopathic pulmonary fibrosis and cancer. Eur Respir Rev 2013; 22(129): 265272.

3. Seo EJ, Ngoc TM, Lee S-M, Kim YS, Jung Y-S. Chrysophanol-8-O-glucoside, an anthraquinone derivative in rhubarb, has antiplatelet and anticoagulant activities. J Pharmacol Sci 2012: 12020206541202020654.

4. Hou K, Lin C, Chen C, Wu B, Wang X, Zhu D. Inhibitory effect of rhubarb on intestinal $\alpha$-glucosidase activity in type 1 diabetic rats. Trop J Pharm Res 2017; 16(6): 1293-1297.

5. Lu CC, Yang JS, Huang AC, Hsia TC, Chou ST, Kuo CL, Lu HF, Lee TH, Wood WG, Chung JG. Chrysophanol induces necrosis through the production of ROS and alteration of ATP levels in J5 human liver cancer cells. Mol Nutr Food Res 2010; 54(7): 967-976.

6. Hong-Kun R, Phil-Dong M, In-Hwa C, Eun-Hee L, HyungMin K. Hyun-Ja J. SoSoSo or its active ingredient chrysophanol regulates production of inflammatory cytokines \& adipokine in both macrophages \& adipocytes. Indian J Med Res 2013; 137(1): 142.

7. Lee MS, Sohn CB. Anti-diabetic properties of chrysophanol and its glucoside from rhubarb rhizome. Biol Pharm Bull 2008; 31(11): 2154-2157.

8. Li A, Liu Y, Zhai L, Wang L, Lin Z, Wang S. Activating peroxisome proliferator-activated receptors (PPARs): $A$ new sight for chrysophanol to treat paraquat-induced lung injury. Inflammation 2016; 39(2): 928-937.

9. Zhang $C$, Song $Y$, Wang $C$, Zhao L, Kang H, Ma X, Wang $J$, Zhang $T$, Shumin $W, M a C$. The effects of chrysophanol on ovalbumin (OVA)-induced chronic lung toxicology by inhibiting Th17 response. Toxicol Mech Methods 2017; 27(5): 327-334.

10. Eberhart CG, Argani P. Wht signaling in human development: beta-catenin nuclear translocation in fetal lung, kidney, placenta, capillaries, adrenal, and cartilage. Pediatr Dev Pathol 2001; 4(4): 351-357.

11. Lam AP, Flozak AS, Russell S, Wei J, Jain M, Mutlu GM, Budinger GS, Feghali-Bostwick CA, Varga J, Gottardi CJ. Nuclear $\beta$-catenin is increased in systemic sclerosis pulmonary fibrosis and promotes lung fibroblast migration and proliferation. Am J Respir Cell Mol Biol 2011; 45(5): 915-922.

12. He W, Dai C, Li Y, Zeng G, Monga SP, Liu Y. Wnt/Bcatenin signaling promotes renal interstitial fibrosis. J Am Soc Nephrol 2009; 20(4): 765-776.

13. Ge W-S, Wang Y-J, Wu J-X, Fan J-G, Chen Y-W, Zhu L. $\beta$-catenin is overexpressed in hepatic fibrosis and blockage of Wnt/B-catenin signaling inhibits hepatic stellate cell activation. Mol Med Report 2014; 9(6): 2145-2151.

14. Care IoLARCo, Animals UoL: Guide for the care and use of laboratory animals: US Department of Health and Human Services, Public Health Service, National, 1986.

15. Cissell DD, Link JM, Hu JC, Athanasiou KA. A modified hydroxyproline assay based on hydrochloric acid in Ehrlich's solution accurately measures tissue collagen

Trop J Pharm Res, May 2020; 19(5): 975 
content. Tissue Engineering Part C: Methods 2017; 23(4): 243-250.

16. Bruce MC, Honaker CE, Cross RJ. Lung fibroblasts undergo apoptosis following alveolarization. Am J Respir Cell Mol Biol 1999; 20(2): 228-236.

17. Raghu G, Weycker D, Edelsberg J, Bradford WZ, Oster G. Incidence and prevalence of idiopathic pulmonary fibrosis. Am J Respir Crit Care Med 2006; 174(7): 810816.

18. Song G, Zhang Y, Yu S, Lv W, Guan Z, Sun M, Wang J. Chrysophanol attenuates airway inflammation and remodeling through nuclear factor-kappa $B$ signaling pathway in asthma. Phytother Res 2019; 33(10): 27022713.

19. Lian $Y$, Xia $X$, Zhao $H$, Zhu $Y$. The potential of chrysophanol in protecting against high fat-induced cardiac injury through Nrf2-regulated anti-inflammation, anti-oxidant and anti-fibrosis in Nrf2 knockout mice. Biomed Pharmacother 2017; 93; 1175-1189.

20. Jia $G$, Wang $Q$, Wang $R$, Deng $D$, Xue L, Shao $N$, Zhang $Y$, Xia X, Zhi F, Yang Y. Tubeimoside-1 induces glioma apoptosis through regulation of $\mathrm{Bax} / \mathrm{Bcl}-2$ and the ROS/Cytochrome C/Caspase-3 pathway. Onco Targets Ther 2015; 8; 303.

21. Li Y, Wang B, Zhou C, Bi Y. Matrine induces apoptosis in angiotensin II-stimulated hyperplasia of cardiac fibroblasts: effects on Bcl-2/Bax expression and caspase-3 activation. Basic Clin Pharmacol Toxicol 2007; 101(1): 1-8.

22. Sharifi S, Barar J, Hejazi MS, Samadi N. Doxorubicin changes Bax/Bcl-XL ratio, caspase- 8 and 9 in breast cancer cells. Adv pharm bull 2015; 5(3): 351.

23. Xie L, Chen Y, Chen J, Zhang H, Liao Y, Zhou Y, Zhou L, Qing C. Anti-tumor effects and mechanism of GA13315, a novel gibberellin derivative, in human lung adenocarcinoma: an in vitro and in vivo study. Cell Mol Biol Lett 2019; 24(1): 1-12.

24. Wei J, Fang F, Lam AP, Sargent JL, Hamburg E, Hinchcliff ME, Gottardi CJ, Atit R, Whitfield ML, Varga J. Wnt/ $\beta$-catenin signaling is hyperactivated in systemic sclerosis and induces Smad-dependent fibrotic responses in mesenchymal cells. Arthritis Rheum 2012; 64(8): 2734-2745.

25. Chilosi M, Poletti V, Zamò A, Lestani M, Montagna L, Piccoli P, Pedron S, Bertaso M, Scarpa A, Murer B. Aberrant $W n t / \beta$-catenin pathway activation in idiopathic pulmonary fibrosis. Am J Pathol 2003; 162(5): 14951502.

26. Henderson WR, Chi EY, Ye X, Nguyen C, Tien Y-t, Zhou $B$, Borok Z, Knight DA, Kahn M. Inhibition of Wnt/Bcatenin/CREB binding protein (CBP) signaling reverses pulmonary fibrosis. P Natl Acad Sci USA 2010; 107(32): 14309-14314. 